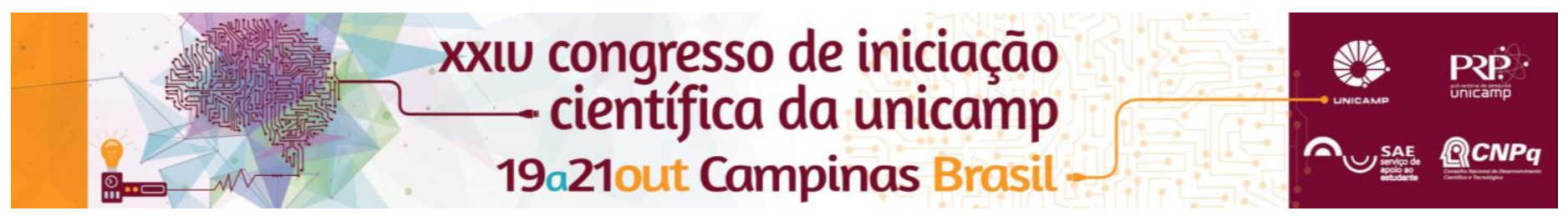

\title{
PRODUÇÃO CIENTÍFICA SOBRE PROPOSTAS E EXPERIÊNCIAS DE FORMAÇÃO DE PROFESSORES PARA O ENSINO DE CIÊNCIAS NOS ANOS INICIAIS DA ESCOLARIZAÇÃO
}

\author{
Deborah Gomes Ribeiro *, Alessandra Aparecida Viveiro.
}

\begin{abstract}
Resumo
Este trabalho, em andamento, tem por objetivo desenvolver um panorama de propostas e experiências de formação de professores para o ensino de ciências nos anos iniciais da escolarização, a partir de levantamento da produção científica sobre o tema. A pesquisa foi realizada em periódicos da área de Ensino de Ciências, selecionados entre os estratos A1, A2 e B1 do Qualis CAPES 2014, em artigos publicados de 2009 a 2015. Encontramos 60 artigos que tratam da Formação de Professores para os Anos Iniciais, explorando diferentes temas.
\end{abstract}

\section{Palavras-chave:}

ensino de ciências, formação de professores, anos iniciais da escolarização.

\section{Introdução}

Ao longo dos últimos anos, a sociedade vem passando por mudanças e como resultado, atualmente, está inserida em um mundo globalizado, onde a informação é acessada de praticamente qualquer lugar, a qualquer hora, por qualquer pessoa. $O$ ser humano está inserido nesse modelo de sociedade desde o momento em que nasce. As descobertas cientificas e tecnológicas agem sobre ele, influenciam seu desenvolvimento e sua maneira de enxergar o mundo e suas relações. Desse modo, a educação em ciências deve ser colocada em prática a partir dos anos iniciais da escolarização. Segundo Harlen (1989), as crianças constroem suas explicações sobre o mundo nessa faixa etária, da escolarização inicial. Para Zancul (2007), as justificativas para se ensinar Ciências nos primeiros anos escolares incluem 0 fato dos conteúdos científicos serem parte da cultura elaborada; o papel que as crianças desempenham como sujeitos sociais frente a diferentes questões; o interesse que elas demonstram frente aos temas de Ciências. Para que essa proposta aconteça, é de extrema importância considerar como ocorre a formação dos professores pois, se eles tiverem a concepção de que ensinar é transmitir conhecimentos prontos, é pouco provável que explorem os conteúdos científicos de forma diversificada, por meio de propostas inovadoras.Diante disso voltamos nosso olhar para a formação de professores. Nosso trabalho, em nível de Iniciação Científica, faz parte de um projeto maior de pesquisa, que tem por objetivo investigar experiências alternativas e propostas de especialistas para a formação inicial de professores para o ensino de ciências nos anos iniciais da escolarização que forneçam subsídios para se repensar os cursos no contexto brasileiro. Neste recorte, o objetivo é desenvolver um panorama de propostas e experiências de formação de professores para o ensino de ciências nos anos iniciais da escolarização, a partir de levantamento da produção científica sobre o tema.

\section{Resultados e Discussão}

A pesquisa foi realizada em alguns periódicos da área de Ensino de Ciências, avaliados entre os estratos A1 e B1 do Qualis CAPES 2014, publicados no período de 2009 a 2015. Inicialmente, utilizamos como critério de busca algumas palavras-chave (formação de professsores combinada com anos iniciais, séries iniciais e crianças). Como obtivemos poucos resultados, retomamos a busca lendo título e, na sequência, resumo de todos os textos publicados no período. A partir desse filtro, selecionamos 60 artigos, conforme a Tabela 1.

Tabela 1. Artigos localizados, por periódico.

\begin{tabular}{|l|c|}
\hline \multicolumn{1}{|c|}{ Periódicos } & Artigos \\
\hline $\begin{array}{l}\text { Alexandria: Revista de Educação em Ciência } \\
\text { e Tecnologia }\end{array}$ & 9 \\
\hline Ensaio: Pesquisa em Educação em Ciências & 6 \\
\hline $\begin{array}{l}\text { Investigações em Ensino de Ciências } \\
\text { Revista Brasileira de Pesquisa em Educação } \\
\text { em Ciências (REBPEC) }\end{array}$ & 10 \\
\hline Revista Ciência \& Educação & 16 \\
\hline \multicolumn{1}{|c|}{ TOTAL } & 60 \\
\hline
\end{tabular}

O material está em análise. Todos os textos foram lidos por completo, para uma breve descrição de cada pesquisa. Organizamos os artigos a partir de temas, entre os quais destacamos: desafios da formação de um professor polivalente, experiências de estágios, uso de diferentes instrumentos e metodologias em sala de aula, espaços alternativos de formação, a concepção que os professores tem sobre o que é Ciência e como ensiná-la, entre outros. Todos os artigos enfatizam a importância e a necessidade da formação de professores contemplar de forma efetiva o ensino de ciências.

\section{Breves Considerações}

O levantamento apresentou diferentes aspectos sobre a formação de professores para o ensino de ciências nos anos iniciais, a partir da análise da produção científica sobre o tema. A continuidade do trabalho prevê a sistematização do material, de forma a trazer contribuições para novas propostas de formação de professores, no âmbito da pesquisa maior em que este projeto se insere.

HARLEN, W. Enseñanza y aprendizaje de las ciencias. Madrid: Morata, 1989 ZANCUL, M. C. S. Ciências no ensino fundamental. In: DEMONTE, A. et al. (Org.) Cadernos de formação: ciências e saúde. 2. ed. São Paulo: Páginas e Letras Editora e Gráfica, UNESP, PróReitoria de Graduação, 2007. 